Acta Poetica $36 \cdot 2$

julio-dicembre

$2015(63-79)$

\title{
Apuntes sobre el mal y el endurecimiento del corazón
}

\author{
Adriana Menassé
}

La decisión que lleva al ser humano a elegir entre el bien y el mal no parece tener explicación racional. Tal es al menos la postura de Kant, así como la de Levinas, quienes dejan la cuestión librada a su misterio último. La formulación que hace la Biblia en el libro del Éxodo, donde nunca es posible saber si Faraón endurece su corazón contra Dios o el propio Dios lo ha endurecido previamente, revela acaso esa misma, profunda ambivalencia. Marlowe y Shakespeare, por su lado, parecen inclinados a la idea de que el mal es una decisión de la voluntad y que su consumación es la ruina espiritual del ser humano. Siguiendo a nuestros clásicos quisiera suponer que el mal (al menos la transgresión y el crimen asumidos a conciencia) es un gesto desesperado - si bien por ello no menos terrible: el alma que claudica en su anhelo de fincar en el sentido, de anudarse a la esperanza.

PALABRAS CLAVE: mal, endurecimiento, sentido, lenguaje.

What makes a human being to decide between right and wrong, between good and evil does not seem to be something that reason can truly comprehend. That is, at least, what both Kant and Levinas suggest, abandoning such decision to its ultimate mystery. The biblical formulation of this enigma can be hinted at in the book of Exodus through the hardening of Pharaoh's heart. Is God hardening the heart of Pharaoh, or was it previously hardened? This question reveals a unique and undecidable movement. Marlowe and Shakespeare also reflect on the hesitations of the soul, supporting the idea that evil is, in the last account, a decision of the will, one that inevitably brings the downfall of its doer. Can the humor of our times adhere to those edifying convictions? Much has happened since Shakespeare and Marlowe's time, but whether our trust in the 
ethical coherence of the world remains vivid or not, we have only an obstinate determination to rely on if we still want to uphold the threads of language and humanity.

KEYWORDS: evil, hardening of the heart, meaning, language.

Fecha de recepción: 14 de agosto de 2014

Fecha de aceptación: 2 de noviembre de 2014 


\author{
Adriana Menassé \\ Universidad Veracruzana \\ Instituto de Filosofía \\ amena993@gmail.com
}

\title{
Apuntes sobre el mal y el endurecimiento del corazón
}

¿Qué pasa cuando el desabrigo de una vulnerabilidad a flor de piel no nos convoca u obliga a la bondad, sino que por el contrario, despierta la tentación de la crueldad y el abuso? ¿Cómo acercarse a la patencia del mal desde una mirada filosófica? En este breve trabajo intentaré reflexionar en torno al pasmo que representa la continua presencia de la impiedad entre los seres humanos, cabeza de medusa cuya visión congela el ánimo. El marco en que se inscriben estas líneas está inicialmente dado por la interrogación que desde el pensamiento levinasiano se abre en torno al mal, habida cuenta de que éste plantea la irrupción de la bondad como fuente de todo lenguaje y de todo sentido. Intentaré presentar un brevísimo recuento de los trazos con que Levinas busca responder a estas preguntas y, al mismo tiempo, seguir los indicios de algunas rutas olvidadas, con la esperanza de echar luz sobre esta espinosa cuestión. El tema del mal, como se ha llamado tradicionalmente, sea el que cae sobre nosotros sin intervención de nuestra parte o el que perpetramos inicuamente sobre nuestros semejantes, constituye uno de los límites que enfrenta la razón. En este sentido, el texto que aquí presento busca acercarse a su interrogación por medio de aproximaciones y tentativas, más que prosiguiendo un argumento lineal. Así, antes que 
plantear conclusiones, este ensayo quisiera sondear algunos de sus dilemas a modo que su claroscuro se haga menos intransitable.

Como sabemos, la noción de "rostro" en el pensamiento de Levinas representa un límite absoluto al ciego deseo de supervivencia y dominio que rige el orden del ser. Según nuestro autor, el desvalimiento radical o fractura última de ese ser que se sabe mortal (y al que Levinas llama "rostro") opera en "mí" - es decir, en cada ser humano que enfrenta a su prójimo - una mutación ontológica, una ruptura que transforma la obstinación de perseverar a expensas de todo o de cualquiera en una exigencia de bondad que se traduce en acción ética, en altruismo o, como lo llama él, en responsabilidad. La ética sería entonces el modo de ser del ser humano, la manera en que "se eleva" sobre su determinación para inscribirse en el significado. En la perspectiva levinasiana no es la guerra lo primero, sino la respuesta que inaugura la hospitalidad y que aparece como la condición misma del lenguaje. Pues el deslumbramiento que ejerce en mí la soberanía del rostro transforma la competencia desnuda en presencia amigable. La respuesta bondadosa constituye el testimonio de la revelación, y actualiza en cada momento la entrada genérica en el espacio significante. Por eso la ética traza nuestro horizonte insuperable.

¿Por qué entonces hay mal y no solamente bien?, se le ha preguntado a Levinas. ¿Qué pasa cuando esa transfiguración no ocurre, cuando el desvalimiento del otro, en vez de atajar el golpe invita a convertirlo en nuestra víctima? Y cómo entender la osadía de un pensamiento que invierte la forma clásica de concebir la sociabilidad en tanto guerra de todos contra todos, para plantear que un movimiento pre-racional conformado como adhesión y cobijo soporta el peso de nuestra condición precaria. ¿Qué no lee los periódicos? Y los genocidios intermitentes, los horrores de las guerras o del totalitarismo de Estado, el racismo, el secuestro, la extorsión - para no hablar de la violencia contra los niños y dentro de la familia, de la explotación de los necesitados-; todas las pequeñas crueldades que perpetramos unos contra otros, ¿cómo habremos de explicarlas?

Mucho se ha dicho en la filosofía acerca del mal, y sin embargo nada nos alcanza para mirar su rostro espeluznante. Porque el mal, como el bien, es inaprensible, imposible de asir o sintetizar en el pensamiento, dice Richard Bernstein en el capítulo que dedica a Levinas en su libro 
El mal radical (247-269). Sin pretensión alguna de ser exhaustivo ni concluyente, Bernstein hace un recorrido por algunas de las respuestas más significativas que de Immanuel Kant a Hannah Arendt se han dado en torno a ese abismo. Pues quizás el mal sea el vacío mismo, el hiato imposible de salvar a pesar del denodado empeño del ser humano por recrear y sostener un mundo inteligible.

Pero Levinas mismo escasamente tematiza la cuestión que aquí nos concierne. Se ocupa sobre todo de la responsabilidad, de la ética como movimiento "opuesto" al ser, o como dice, "de otro modo que ser". Dicha fórmula no se traduciría por "ser de otro modo", sino por "constituirse de una manera distinta al ser". La excedencia que se da en la expresión del rostro (en su vulnerabilidad sin aspaviento) sólo puede ser respondida con otra desproporción, con la gratuidad de la acción recta, con el movimiento hacia la "altura", dice, de la justicia. El campo de guerra y violencia ha encontrado expresión en cierta lectura del conatus spinoziano y en la voluntad de poder en Nietzsche: voluntad sin coto, deseo de perdurar frente a todo lo que se le oponga. La ética interrumpe esa continuidad: sobreviene. Sobreviene como un deslumbramiento, como un mandato trascendente que detiene la mano asesina. Entonces, en un primer nivel podríamos decir que la violencia, como la crueldad incluso, el arrogante ejercicio del poder, representa para Levinas lo previsible, lo conocido, pues apunta a la inercia propia del ser al que también estamos inevitablemente anclados. En el pensamiento de Levinas habría una "propensión natural al mal" — si por mal entendemos dicho afán de autoafirmación sin límite o medida-. Lo extraordinario no sería entonces el abuso, sino la irrupción de una generosidad que pospone la necesidad propia en beneficio de la petición que viene del otro; no tanto la violencia como la suspensión del ataque para dar cabida a la abnegación y la gratitud. La ética como interrupción de la ley del ser instituye el orden humano como orden de sentido. Y si todos los seres humanos somos incluidos en el lenguaje a través del amor (del alimento elemental y la palabra que nos dirige una voz protectora), la significación ha de ser continuamente sostenida y renovada. El sentido se configura como ejercicio de adhesión y entrega al mandato de justicia, pues sólo éste preserva la confianza básica y la buena voluntad sobre la que se tiende nuestro diálogo. 
¿Cómo explicar entonces que no siempre obedezcamos el mandamiento, que el rostro de nuestro prójimo sea impotente para movernos a la bondad, que prevalezca la indiferencia ante el sufrimiento ajeno o, incluso, que dé paso a la perversión más inicua? Nada parece adecuado para dar respuesta a esa cuestión última. El mal como pregunta filosófica no ha dejado de sacudir la comprensión que el ser humano tiene de sí mismo, su búsqueda continua de propósito y la imagen que adivina con respecto a las mejores posibilidades de su condición. No se trata, sin duda, de una pregunta novedosa. Ya en los textos más antiguos de la tradición occidental (y seguramente de todas las otras tradiciones, puesto que todas han debido dar respuesta al punzante rencor que nos habita) aparece una y otra vez la pregunta por aquello que trastorna y confunde nuestra fe en el mundo. ¿Será que el bello mundo de sentido en el que amamos y conversamos es apenas una frágil ilusión?, ¿que el criminal y el estafador prosperan sin daño, y la moralidad entera es un pasatiempo de niños?

Son éstas las preguntas que no cejan en su insistencia y cuyas precarias orientaciones siguen alimentando el más radical de los anhelos, el anhelo de bondad. Quisiéramos escuchar las voces que nos llegan desde las cumbres de esta tradición: desde la inescrutable formulación bíblica en torno al endurecimiento del corazón hasta las voces de nuestras obras clásicas, las que susurran a nuestro oído siempre nuevos significados. Sólo entonces podremos inquirir si aquellos escritos optimistas y edificantes siguen sustentando nuestra fe en la bondad fundamental del mundo o si han perdido del todo su poder de convicción. ¿Hay algo que hoy sostenga una vocación moral cada vez más corroída desde el interior y el exterior? Esbozos, apuntes, destellos acaso, en una selva de contradicciones.

\section{La formulación bíblica}

¿Cómo es, preguntábamos arriba, que la elocuencia desnuda del rostro, que la irrupción de esa verdad sin argumentos que hace brotar la hospitalidad en el corazón se convierte tantas veces en el lugar de una violencia que supera incluso el deseo de dominio? Al menos desde Freud 
sabemos que la buena voluntad no es algo que dependa solamente de la razón correcta. El presupuesto de fuerzas inconscientes, de poderosos impulsos eróticos y pulsiones destructivas que actúan al margen o por encima de la razón forma hoy parte de nuestro bagaje de conocimiento compartido. Hay que decir que Freud no desprecia el papel medular que, siempre frágil y amenazado, tienen en la vida de las sociedades los imperativos éticos. No basta con decir que los brotes de violencia, guerra o destrucción de los valores civilizatorios, que los actos de crueldad que ejercemos unos contra otros o que otros han ejercido contra nosotros constituyen la prueba de esas fuerzas inconscientes que no acaban nunca de controlarse. ¿No es el rostro, al menos en la perspectiva levinasiana, el temblor que suspende el ímpetu salvaje para dar paso a la adhesión y la ternura? También Kant presuponía el respeto universal por la razón práctica y la clara aprehensión del imperativo de la acción racional sin necesidad de filósofos ni de filosofías. Entonces ¿cómo entender su fracaso?

A pesar de lo mucho que se ha dicho en la filosofía sobre el mal, quisiéramos referirnos a la formulación bíblica de la cuestión, pues nos parece vislumbrar allí algunos indicios que pudieran echar luz sobre esta paradoja. Como todos los grandes pasajes bíblicos, éste ha soportado un sinnúmero de interpretaciones y comentarios. No pretendemos, naturalmente, presentar una lectura, ahora sí, definitiva; por el contrario, como sucede con los grandes escritos, nos acercarnos al rumor de su venero para escucharlo como si fuera la primera vez. El tema del endurecimiento del corazón, del acto de insensibilidad y repudio de la justicia puede pensarse fuera o más allá del relato donde esta fórmula aparece repetidamente; pero la imagen del corazón endurecido, con las consecuencias de soberbia y crueldad que conlleva la imagen, difícilmente ha sido superada por la literatura posterior. Y si el enigma de dicho endurecimiento no termina de entregar nunca su secreto, nos permite habitar por instantes el centro mismo de su contradicción.

Como recordaremos, hay una expresión en el libro del Éxodo que presenta de manera bastante precisa el misterio de la maldad en la actuación humana. Cuando Dios se dirige a Moisés para ordenarle que hable con Faraón y le pida que deje salir al pueblo hebreo, el texto hace decir a Dios: "Cuando hayas vuelto a Egipto, mira que hagas delante de 
Faraón todas las maravillas que he puesto en tu mano; pero yo endureceré su corazón de modo que no dejará ir al pueblo" (4:21). ${ }^{1}$ Un poco más adelante, cuando Aarón y Moisés van ante Faraón y hacen los actos de magia que Dios les ha ordenado, Faraón se burla de ellos diciendo que no necesita a Jehová para esos trucos. El texto dice aquí: "Entonces llamó también Faraón sabios y hechiceros e hicieron también lo mismo los hechiceros de Egipto con sus encantamientos; pues echó cada uno su vara, las cuales se volvieron culebras; mas la vara de Aarón devoró las varas de ellos. Y el corazón de Faraón se endureció como Jehová lo había dicho" (7: 11-13). Vienen después las plagas con que Jehová hiere a Faraón, pero el corazón de éste una y otra vez se endurece. Porque si el acto de crueldad consiste sobre todo en la imposibilidad de escuchar el mandamiento que nos llega desde el rostro desnudo de nuestro prójimo (y aun considerando la coartada con que la crueldad quiere hacerse pasar por justicia), el tema del endurecimiento se convierte en el nudo central de nuestra investigación. ${ }^{2}$

La pregunta obligada y largamente discutida consiste en plantear quién endurece el corazón de Faraón. Si Dios lo hace, ¿cómo puede pedirle cuentas de sus actos? ¿Y con qué objeto haría Dios eso? ¿O es Faraón el que endurece su propio corazón, como se insinúa en otras ocasiones; es decir, que se endurece contra los mandatos de Dios, y por tanto es responsable de dicho endurecimiento? Son varias las respuestas que se han dado en la literatura bíblica, pero me interesa explorar esta ambigüedad a la luz del tema que nos ocupa. Aquellos que "han endurecido su corazón" no consiguen escuchar los mandatos de Dios, es decir, no pueden escuchar la voz que llama desde el rostro, pues el rostro sólo habla a quien está dispuesto a la escucha. Ante los oídos sordos el rostro enmudece y se convierte en una cifra, en un signo que descubre simplemente una debilidad o un quebranto que invita a la violencia. ¿Nos encontramos en el ojo de un pensamiento circular, de una petición de principio?

${ }^{1}$ Todas las citas bíblicas están tomadas de la versión de Casiodoro de Reina (1569), revisada por Cipriano de Valera (1602) y otras revisiones (1960).

${ }^{2}$ Hay otros momentos en el cuerpo textual bíblico donde ocurre la expresión "endurecer o endurecimiento del corazón" (Salmos 95: 7-8, Isaías 6: 9-10, Romanos 9:17-18, Romanos 11: 23-26, Hebreos 3:7-10). Me referiré aquí solamente a las que aparecen en el libro del Éxodo 7-10. 
Aunque tal vez sea esta ambigüedad la que descubra alguna señal que nos permita salir — que nos permita adentrarnos en el laberinto.

Dios endurece el corazón de Faraón. Algunos de los estudios sobre el lenguaje de la Biblia quisieran resolver el asunto planteando que la expresión "endurecer el corazón" en su forma pasiva (es decir, donde el sujeto recibe la acción del endurecimiento por parte de Dios) constituye una fórmula coloquial del hebreo que en realidad apunta a su forma activa: el sujeto, en este caso Faraón, endurece su corazón. Otros dicen que Dios no endurece el corazón de Faraón, sino que establece las condiciones a partir de las que el corazón se endurece y, en ese sentido, permite que se endurezca. La responsabilidad, sin embargo, recae totalmente sobre Faraón. ${ }^{3}$ El texto, sin embargo, da pie para entenderlo de tres maneras diferentes: ocho veces en la narración Dios endurece el corazón de Faraón; seis veces el corazón de Faraón "se endurece" sin referencia a quién realiza la acción, y tres veces Faraón endurece su propio corazón. ${ }^{4}$ En Éxodo 9:34, 9:35 y 10:1, que son tres versículos seguidos, encontramos juntas estas tres versiones o matices de la misma idea. Dice:

${ }^{3}$ Véase por ejemplo K. Butt \& D. Miller “¿Quién endureció el corazón de Faraón?”. Apologetics Press (apologeticspress.org): "En su gran obra sobre las figuras bíblicas de expresión, E.W. Bullinger listó varias maneras en que los idiomas griego y hebreo usaban verbos para expresar algo diferente a su uso estricto y literal. Él listó varios versículos que muestran que los idiomas 'usaban verbos activos para expresar el diseño o intención del agente para hacer algo, incluso cuando no se hacía realmente eso' (1898, $821) \ldots$ [La] cuarta lista de Bullinger en cuanto a los verbos idiomáticos habla de los verbos activos que 'los hebreos usaban para expresar, no la ejecución de algo, sino el permiso de lo que se dice que el agente hace' (823, énfasis en original). Como una ilustración, al comentar sobre Éxodo 4:21, Bullinger anotó: 'Yo endureceré su corazón (i.e., permitiré o toleraré que su corazón se endurezca), de modo que no dejará ir al pueblo'. Éste es el mismo sentido en todos los pasajes que hablan del endurecimiento del corazón de Faraón, como también es claro por el uso común de la misma expresión en los siguientes pasajes' $(1968,823)$. En una sección larga sobre las expresiones bíblicas, James MacKnight concuerda con el enunciado de Bullinger que en el hebreo los verbos activos pueden expresar permiso y no la acción directa. Esta explicación sin duda clarifica el tema del endurecimiento del corazón de Faraón. Cuando el texto dice que Dios endureció el corazón de Faraón, esto significa que Dios permitió o toleró que el corazón de Faraón se endureciera".

${ }^{4}$ Cfr. Éxodo. Faraón endurece su corazón: Ex. 8:15, 8:32, 9:34, el corazón de Faraón se endurece: $7: 13,7: 22,8: 19,9: 7,9: 35,13: 15$, Jehová endurece el corazón de Faraón: 9: 12, 10:1, 10:20, 10:27, 11:10, 14:4, 14:8, 14:17. 
9:34 Y viendo Faraón que la lluvia había cesado, y el granizo y los truenos, se obstinó en pecar, y endurecieron su corazón él y sus siervos.

9:35 Y el corazón de Farón se endureció, y no dejó ir a los hijos de Israel, como Jehová lo había dicho por medio de Moisés.

10: 1 Jehová dijo a Moisés: Entra a la presencia del Faraón; porque yo he endurecido su corazón y el corazón de sus siervos, para mostrar entre ellos éstas mis señales.

Como se ve, en el primer versículo citado Faraón y sus siervos "endurecieron su corazón"; en el segundo, el corazón de Faraón "se endureció", y en el tercero Dios toma responsabilidad por haber endurecido el corazón de éstos. ¿Quiere decir que estas tres modalidades del endurecimiento en realidad son una sola, y que la acción de Dios al endurecer el corazón del ser humano, la del ser humano que endurece su corazón y el hecho de que el corazón se endurezca constituyen una unidad indisoluble? ¿Y qué significa esto para la ética?

Decíamos que el rostro sólo puede hablar a quien tiene corazón para escucharlo. Cuando el interlocutor tiene el corazón endurecido, el otro se convierte en una forma indescifrable que sólo delata una fragilidad inútil, que ya no transmite ningún mensaje ni abre el espacio del intercambio humano, pues éste supone y sostiene la bondad como mandato. Aunque, si Dios ha endurecido su corazón, ¿cómo puede hacerse responsable a quien es sólo su víctima? He aquí tal vez la fuerza de ese antiguo desafío: debemos responder por el endurecimiento de nuestro corazón aun cuando dicho endurecimiento sea producto de una herida que nos viene de fuera. Porque es siempre la vida, los otros, el mundo (¿Dios?) el que nos lastima, y nuestra fragilidad apenas logra resistir tales embates. Freud diría que los choques que sufrimos vienen tanto de dentro como de fuera: de la pulsión de nuestros instintos y de la represión que nos impone el mundo. Y nuestra psique o nuestro yo se acomoda a medias y con trabajos a las exigencias de los otros. El endurecimiento sería en parte un recurso de madurez, un recurso para la supervivencia e incluso para una vida vivida junto a los demás. Pero también es Freud quien descubre para el pensamiento el universo de los deseos reprimidos, las pulsiones congeladas que inevitablemente quedan al acecho, así como las heridas que nos inflige lo que llamamos "realidad" y cuyos efec- 
tos - llagas entumecidas de dolor y rabia - apenas serían imputables a la conciencia. Bajo esa capa de olvido y pesar mal concertado se articula lo que hoy conocemos de manera genérica como "inconsciente". 5

El endurecimiento dejaría de ser un acto de la conciencia, incluso de una conciencia inclinada por la voluntad; los versículos citados estarían más bien apuntando a ese espesor, a la densidad de ese espacio nebuloso en el que se juega la decisión moral. La ambivalencia de esas líneas - donde nunca se define del todo si es Faraón responsable de su endurecimiento; si, por el contrario, nada puede contra el hecho de que Dios lo ha endurecido, o si constata simplemente que la insensibilidad se ha apoderado de él - parecen apuntar al lugar de una trabazón indecidible. De manera inversa pero equivalente al nudo misterioso en que Jehová endurece el corazón que el Faraón ya había endurecido, tal vez la ética misma, la justicia y el candor que asoman en ese rostro que le habla al corazón se entregan por medio de un gesto único, de un acto que es al mismo tiempo voluntad y gracia, pasividad y elección.

\section{Nuestros clásicos}

¿Quién responde entonces? ¿Somos tan sólo el entramado de las fuerzas que nos atraviesan, dejándonos inermes frente a nuestros actos? Vale la

5 Estas nociones básicas se encuentran amplia y reiteradamente expuestas en el corpus freudiano. Cito algunos pasajes alusivos al tema que nos concierne, así como algunos comentarios de Bernstein en el trabajo mencionado. Dice Freud, por ejemplo, en Más allá del principio del placer: "Existe, efectivamente, en el alma, una fuerte tendencia al principio del placer; pero a esta tendencia se oponen, en cambio, otras fuerzas o estados determinados, y de tal manera que el resultado final no puede corresponder siempre a ella" (1972b: 85). Respecto a la necesidad de una ponderación equilibrada del poder de las dos fuerzas elementales en la obra de Freud, la erótica y la destructiva, comenta Bernstein: "En realidad no existe algo así como 'erradicar' el mal. Freud nos alerta sobre la tentación de dejarse seducir por los opuestos extremos: atribuirle demasiada rigidez a la 'parte innata' de la naturaleza humana, y 'sobreestimar la susceptibilidad total de la cultura en comparación con la porción de vida instintual que ha permanecido primitiva'... Algunos comentaristas han opinado que el mensaje básico de Freud es pesimista y que abandona cualquier esperanza ilustrada en cuanto a la eficacia de la razón. Pero eso es injustificado. Freud busca ilustrarse honestamente sobre la razón misma, y nos insta a ser más realistas sobre su fragilidad y sus limitaciones" (215-216). 
pena señalar cómo las obras señeras de nuestra cultura reflexionan sobre este tema medular, el lugar donde se juega la pregunta por la ética. Pues por más delicada que sea la fragilidad que nos habita, también nuestra razón o nuestra intuición insisten en que hay un momento cuando el sujeto ha de hacerse responsable de sus decisiones. Debemos suponer que en medio de la pesadumbre hay un instante cuando la voluntad decide dar cabida a la amargura y convertirse en el instrumento de su venganza. Así, por ejemplo, el Fausto de Marlowe revela, con la frescura y la fuerza de un lenguaje desenfadado, el paso que va de la tentación al acto, del impulso a la determinación: Fausto se inflige una herida para sellar su pacto con el diablo, y la sangre se niega a correr. Entonces el diablo acerca una vela encendida, descongela la sangre y Fausto firma. El designio que lleva el ánimo a la insolencia y la crueldad aparece aquí como un exceso avalado por la conciencia, aun cuando el núcleo de tal decisión sea insondable.

Acaso nos veamos llevados a afirmar (en la medida en que dicha certidumbre sostiene la significación sobre la que reposamos) que por más que los golpes del mundo se agiten contra nosotros, "algo" debe resistir (o simplemente algo resiste algunas veces) sin que podamos dar cuenta de ello. Un presentimiento, un deseo arraigado se niega a ceder ante el dolor su anhelo de vínculo y de encuentro. Otro, en cambio, no resiste y cede a la congoja y a la rabia. Job, azotado por los males, recibió la gracia porque en su incomprensión no cerró la posibilidad de ser salvado. Aceptó finalmente de Dios el mal tanto como el bien, y pudo volver a orar y a bendecir. Pero el santo Job fue en realidad afortunado, pues había gozado la bendición antes de probar los azotes. ¿Puede alguien agradecer en su corazón cuando no ha conocido la dulzura que hace germinar la benevolencia? ¿Es posible sostener la candidez, digamos, sobre un puro anhelo de contacto? Tal vez uno de los propósitos centrales de las religiones sea ofrecer un asidero que permita al ser humano enfrentar la adversidad y conservar, a pesar de todo, un corazón de carne.

Porque el ser humano - y ésta es la propuesta que aquí aventuramos- desearía ante todo dejarse conmover por el llamado de la trascendencia: sólo así es posible dar cabida a la esperanza y al amor. El mal delataría la imposibilidad de ese impulso primario y de esa vocación última. Como Mefistófeles en el Fausto al que aludimos arriba, el 
alma lamenta no estar en la presencia divina. Cuando Fausto increpa al diablo preguntándole dónde está el infierno, Mefistófeles contesta: "El infierno está donde estamos nosotros / y nosotros estamos por siempre donde esté el infierno..." (Marlowe 1983: 63; cfr. versión original en 1962: 101-161). ${ }^{6} \mathrm{Si}$ es cierto que el sujeto busca la satisfacción de sus necesidades y apetitos, no lo es menos su deseo de deponer, o al menos posponer, su voluntad de poder para inscribirse en un orden de confianza y de sentido. El bien sería entonces nuestro anhelo más íntimo. Vivir en un orden de sentido; vivir de cara a la posibilidad del amor. El mal aparecería, desde esta perspectiva, como el fracaso de dicho anhelo, como un acto de renuncia y una proclama de abatimiento. Sólo entonces la desesperanza se vuelve indiferencia y se niega a la complicidad del coloquio y el acuerdo fraterno. El mal constituiría la tristeza más definitiva, un gesto desesperado. ¿No es esta convicción la apuesta radical de la cultura, el sustrato de nuestros mitos y de nuestras adhesiones?

También Macbeth, el noble guerrero, cede a la tentación para quedar atrapado en las redes del exceso y la desesperanza. Macbeth no se ve impelido por la aflicción y la ira a endurecer su corazón contra el rey Duncan y a perpetrar los crímenes desencadenados por ese primer asesinato. Tampoco, como sería posible pensar de Faraón, porque se aferra a lo que cree que le es debido conforme a su poder. Macbeth cede a la tentación del mal por un "error" de cálculo, por el "tropiezo" al que lo conducen las palabras de las brujas. Buscaba dar curso a su potencia plena, alcanzar sin demora la gloria que le ofrecen y que parece estar tan a la mano. Con la lógica más rigurosa, sin embargo, Shakespeare lleva a su protagonista a los límites del significado, al lugar donde se le hace imposible leer su propia vida. No otra cosa es el célebre parlamento del antihéroe frente a la noticia de la muerte de su compañera, parlamento que de un golpe ilumina y condensa la tragedia:

6 "Mephostophilis.-Now Faustus, ask what thou wilt.

Faustus.-First will I question with thee about hell. Tell me, where is the place that men call hell?

Mephost.-Under the heavens.

Faustus.-Ay, so are all things else; but whereabouts?

Mephost.-Within the bowels of these elements, / Where we are tortured and remain forever. / Hell hath no limits nor is circumscribed / In one self place, but where we are is hell, / And where hell is, there we must ever be..." (117). 
MACBETH. Mañana y mañana y mañana

Arrastra su paso insustancial día con día

Hasta la última sílaba del tiempo destinado;

$Y$ todos los ayeres conducen nuestra senda

Al polvo de la muerte. ¡Apágate ya, breve candela!

La vida es apenas una sombra, un pobre actor

Que sufre y que se agita por la escena,

Y pronto deja de escucharse. Es una historia

Contada por un loco, llena de ruidos y de furia,

Que nada significa.

(Act. V, 5; trad. mía)

No es la voz de Shakespeare la que habla en estas líneas, como a veces suponen los críticos: es el malvado que llega al final de su camino y se encuentra frente a la mueca horrorosa del vacío. El lenguaje se disgrega cuando los lazos de amistad que tendemos hacia los demás dejan de transmitir sus señales. Lady Macbeth, su cómplice y sostén (la más fría y compuesta villana de la literatura), muere trastornada por las manchas de sangre que no puede lavar ya de sus manos. El pecado de hibris al que sucumbe Macbeth consiste en creer que podía aventurarse en el crimen sin quedar atrapado en su vértigo. Macbeth lo paga con su caída y malogrado fin. Shakespeare muestra la estricta concatenación de acontecimientos que conducen a la demencia y a la muerte. "No dormirás más", escucha decir Macbeth momentos después de que ha cometido el acto. "Macbeth ha asesinado el sueño, al inocente Sueño". Muerte del sueño, desgarramiento del manto de signos que nos cobija, corriente de guiños en la que nos reconocemos.

La sensibilidad posmoderna se preguntará, sin duda, si ese aliento optimista de nuestras referencias canónicas puede sostenerse más allá de su contexto. Pues está ante todo la banalidad del mal, la cantidad de crueldades grandes y pequeñas cuya profundidad y envergadura queda velada para quien las comete. Y la vida continúa aparentemente sin que los perpetradores sucumban a la vacuidad de la existencia. ¿Desesperan los corruptos y asesinos que traspasan los límites de la moralidad para transitar los caminos del desenfreno? ¿Y los torturadores que en nombre de alguna "idea" dan rienda suelta a la impiedad y el sadismo? 
El tema es tan viejo como el mundo, y Job mismo se queja a Dios preguntando: “¿Por qué viven los impíos / Y se envejecen, y aun crecen en riquezas?... / Sus casas están a salvo del temor, / ni viene azote de Dios sobre ellos" (21: 7-9).

Cuando matamos las fuentes de la fragilidad, cuando se endurece el centro sensible a partir del que establecemos contacto con el otro, se destrenza el lazo que nos une a los demás; la invitación que es el Otro se cancela y la desprotección de su rostro introduce la tentación del poder absoluto. Después, seguramente la costumbre y la familiaridad con la violencia hacen lo suyo, curtiendo y disgregando nuestro espíritu.

¿Debemos creer a nuestros clásicos cuando nos dicen que la impudicia y el crimen excluyen del entusiasmo y del amor a quienes, como Lucifer, traspasan los límites para adueñarse del principio común en que nacemos y habitamos? La insolencia desgarra el tejido donde anidan la proximidad y la entereza, todo lo que convierte al mundo en fuente de gratitud y alegría sin la que cualquier otra posesión se vuelve irrelevante. Sólo la integridad que resiste la seducción de la soberbia nos protege de los vientos letales contra los que no tenemos defensa cuando hemos derribado las barreras de lo permisible. De Macbeth a Pedro Páramo, del Fausto isabelino al Kurtz del Corazón de las tinieblas, el malvado sucumbe a su propio exceso. Cada acto de arrogancia cimbra la vida de la especie, pero una débil fuerza humanizadora que se niega a desaparecer vuelve a tantear los linderos de nuestra fragilidad insalvable para preguntar: "¿qué nos ha sido vedado?".

No sé si la primaria certeza que nos ofrecen estos símbolos sea una apuesta jovial, un frágil deseo y un precario asidero para la ética, pero la intuición que se expresa en las más entrañables referencias de nuestra cultura nos sujeta a su promesa rotunda. Si a la pregunta de Job responde el torbellino de la creación misma, la pregunta por los márgenes que somos supone que sólo la franqueza y la rectitud son capaces de proteger nuestro noble abandono. Ningún vínculo funciona sin la ciega fe a la que nos convoca el lenguaje, y por eso mismo todo lenguaje guarda en su seno la posibilidad de la mentira. Es posible mentir y asesinar sin que caigan los cielos sobre la cabeza de los perpetradores, pero la significación y el amor se sostienen sobre la ingenuidad primaria. Desgarrar 
el velo nos arroja a la soledad de la intemperie, allí donde la temeridad ha desgarrado la inocencia y asoma la mueca grotesca del vacío.

O tal vez no, y acaso el tufo de la corrupción no nos mate ni embote del todo nuestros sentidos. ¿Cuánta maldad cotidiana es redimible? Fausto comienza su periplo haciendo travesuras inocuas, pero la inmunidad que goza lo lleva a la insolencia procaz. Su condena no está sellada todavía. Sólo cuando destruye el resquicio de sensibilidad que le quedaba y manda torturar y asesinar al anciano que ha hablado a su corazón, sólo entonces Fausto se condena sin remedio. Sin duda, nuestro universo de símbolos está allí para preservarnos de la carcajada sacrílega. ¿Debemos decir con Platón ante el mito de Er al final de la República: "si pudiéramos creerlo, estaríamos salvados"? Estaríamos salvados si lo creyéramos. Un velo que oculta la visión espantable de la nada. Es posible.

¿Y podemos creerlo ahora? Desde que Hannah Arendt escribió su libro sobre el juicio de Eichmann en Jerusalén y llegó a la conclusión de que ni Eichmann se sentía culpable ni guardaba motivaciones particularmente malévolas; que el más terrible daño puede ser cometido por razones banales sin que colapse la visión del mundo o la comprensión que el perpetrador tiene de sí mismo; desde entonces, digo, toda la inmensa energía puesta en la idea de que el malvado sucumbe a su pecado se torna quebradiza y soporta con dificultad el peso de nuestras interrogantes. ¿Renunciaremos al intento de hacer inteligible el orden que habitamos?

Como Job, no estábamos allí el día en que Dios fundaba la tierra ni nos es dado penetrar todos los misterios. Nos queda, para orientarnos, sólo un compromiso obstinado, irreductible, con la rectitud y la justicia si hemos de sostener con nuestra entrega las condiciones que hacen posible la lealtad; si la honradez que se opone a la tentación del abuso todavía ha de imantar el espacio en que se trenzan los empeños más nobles, la dicha del asombro y el abrazo confiado.

\section{BIBLIOGRAFÍA}

Bernstein, Richard. El mal radical [2002]. Trad Marcello G. Burello. México: Lilmod-Fineo, 2006. 
Butt, Kyle y Dave Miller. “¿Quién endureció el corazón de Faraón?”, en Apologetics Press. Artículo en línea disponible en $<$ http://espanol/apologeticspress.org/espanol/articulos/3486> [fecha de consulta: 14 de julio de 2014].

ConRaD, Joseph. El corazón de las tinieblas. Trad. Sergio Pitol. Barcelona: Orbis, 1986.

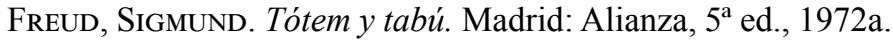

Freud, Sigmund. "Más allá del principio de placer", en Psicología de las masas. Madrid: Alianza, 1972b: 81-137.

Freud, Sigmund. El malestar en la cultura. Madrid: Alianza, $5^{\text {a }}$ ed., 1979.

Levinas, Emmanuel. Totalidad e Infinito [1971]. Salamanca: Sígueme, 1977.

Levinas, Emmanuel. Ethique et Infini. Dialogues avec Phillipe Nemo. Paris: Librairie Arteme Fayard et Radio France, 1982.

Levinas, Emmanuel. De Dios que viene a la idea. Madrid: Caparrós, 2001.

Marlowe, Christopher. Doctor Faustus. The Genius of the Early English Theater. New York: The New American Library, 1962.

Marlowe, Christopher. La trágica historia del Doctor Fausto. Trad. Marcelo Cohen. Barcelona: Icaria Literaria, 1983.

Santa Biblia. Antigua versión de Casiodoro de Reina (1569) revisada por Cipriano de Valera (1602) y otras revisiones: $1862,1909,1960$. Sociedades Bíblicas de América, 1960.

ShaKespeare, William. Macbeth. Complete Works of William Shakespeare. New York: Avanel Books, 1955. 